This is a self-archived - parallel published version of this article in the publication archive of the University of Vaasa. It might differ from the original.

\title{
Review of Industry 4.0 in the Light of Sociotechnical System Theory and Competence- Based View: A Future Research Agenda for the Evolute Approach
}

Author(s): Imran, Faisal; Kantola, Jussi

Title: $\quad$ Review of Industry 4.0 in the Light of Sociotechnical System Theory and Competence-Based View: A Future Research Agenda for the Evolute Approach

Year: $\quad 2019$

Version: Accepted manuscript

Copyright (C) 2019 Springer. This is a post-peer-review, pre-copyedit version of an article published in Advances in Human Factors, Business Management and Society. The final authenticated version is available online at: https://doi.org/10.1007/978-3-319-94709-9_12

\section{Please cite the original version:}

Imran, F. \& Kantola, J. (2019). Review of Industry 4.0 in the Light of Sociotechnical System Theory and Competence-Based View: A Future Research Agenda for the Evolute Approach. In: Kantola, J. I., Nazir, S. \& Barath, T. (eds.) Advances in Human Factors, Business Management and Society, 118-128. Advances in intelligent systems and computing, vol. 783. Cham: Springer. https://doi.org/10.1007/978-3319-94709-9_12 


\title{
Review of Industry 4.0 in the Light of Sociotechnical System Theory and Competence-Based View: A Future Research Agenda for the Evolute Approach
}

\author{
Faisal Imran ${ }^{1 *}$ and Jussi Kantola ${ }^{1}$ \\ ${ }^{1}$ School of technology and innovations, University of Vaasa, 65101 Vaasa, Finland \\ *fimran@uva.fi
}

\begin{abstract}
This paper reviews the concept of Industry 4.0 related challenges and basic requirements for successful implementation of it. It proposed that sociotechnical system theory (STS) and competence-based view (CBV) are best approaches towards implementation of industry 4.0 in the organizations. STS theory leads to such systems, which are more acceptable to end users and deliver better value. While competencebased view prepare those users to interact efficiently with new systems. To support competence-based view for industry 4.0 we argue that competence models of the Evolute approach need to be revised and updated, as well as, there is need for new competence models for emerging new job profiles. The combination of these three approaches will result into successful implementation of new industry 4.0 systems in the organizations.
\end{abstract}

Keywords: Industry 4.0, Sociotechnical System Theory, Evolute, Competence-Based View, Competence models, Digitalization, IoT

\section{Introduction}

The digital revolution has been unfolding for decades and its impact on business and society has been visibly accelerating since the start of the new century. But from past one decade, the exponential evolution of modern technologies like Industrial Internet of Things (IIoT), cloud computing, advanced algorithms, artificial intelligence, hyper-connectivity, selflearning systems, automation, big data and analytics are leading us to ever smarter systems, machines, products and factories [1]. Based on this trend, the term "Industry 4.0" (also wellknown as fourth industrial revolution) emerged, which refers to "the digitization/digitalization of the manufacturing sector, with implanted sensors in virtually all product components and manufacturing equipment, ubiquitous cyber-physical systems, and analysis of all related data [2]. Unlike past industrial revolutions, it is supported by a fusion of technologies, which is blurring the lines between the physical, digital, and biological spheres [3]. As per its current velocity of occurring, it is much more disruptive as compared to past technologies. On one hand, it will make firms much more efficient and 
productive with new technological capabilities and on the other hand, it will pose new challenges for organizations and people [1], [3]. It requires new skills, knowledge and competencies to manage these technologies as well as require more flexible working environment in the organizations [4].

The main objective of this paper is to discuss the Industry 4.0 with respect to its basic concepts, history, and challenges. We have chosen two approaches to discuss industry 4.0, which are sociotechnical system (STS) theory and competence-based view (CBV). The reason behind these choices is to approach industry 4.0 from social aspect. Sociotechnical system theory accounts for social factors while implementing new technologies [5]-[7]. It discusses changes in working practices and social issues during the design and implementation of new technologies. It considers both technical and social issues in quest of promoting change in the organizations [3], [8]. Moreover, we argue that competencebased view strengthens the social part of STS theory, especially in this fourth industrial age, where more flexible work environment is required in the organizations [9]. Finally, we discuss the Evolute system approach and Co-Evolute methodology to further support the social part of STS theory. Co-Evolute methodology helps organizations in analyzing and improving human resources and organizational processes by providing competence analysis [10]-[12]. Most of the Evolute tools were developed before the start of new industrial age, therefore, the last objective of this paper is to provide a future research agenda for Evolute approach.

\section{Industry 4.0}

In recent years, Industry 4.0 has been introduced as a popular term to describe the trend towards digitization and automation of the manufacturing environment [9]. Nowadays, the visionary idea of Industry 4.0 or other synonyms like smart manufacturing, smart production or Industrial Internet of Things (IIoT), have been increasingly promoted by different actors to describe the trend towards digitization, automation and the increasing use of ICT in the manufacturing environment [13]. German government coined this term "Industry 4.0" to refer their initiative towards hi-tech strategy for 2020 [13]. It is also known as fourth industrial revolution, following the earlier three revolutions of mechanization (due to invention of steam engine), mass production (electricity energy replacing the steam engine) and automation/computerization/digitization (usage of information technology and electronics) [13]. The core idea of all these paradigms was to improve production operations to enhance organizational profitability. First industrial revolution improved productivity by introducing steam engines, second enabled mass production through usage of electricity energy, third enhanced the production efficiency by using IT and electronics [1], while this fourth industrial revolution is enabling organizations in mass customization by using advanced, smart and hyper-connected technologies [1]. In following, table1 summarizes all these four paradigms: 
Table 1. Industrial Revolutions [1], [13]

\begin{tabular}{|c|c|c|c|c|}
\hline & $1^{\text {st }}$ Revolution & $2^{\text {nd }}$ Revolution & $3^{\text {rd }}$ Revolution & $4^{\text {th }}$ Revolution \\
\hline Names & Mechanization & $\begin{array}{c}\text { Mass } \\
\text { Production }\end{array}$ & $\begin{array}{c}\text { Computerization } \\
\text { Automation }\end{array}$ & Robotization \\
\hline Time Period & $\begin{array}{c}\text { Late } 18^{\text {th }} \text { to Early } \\
19^{\text {th }} \text { century }\end{array}$ & $\begin{array}{l}\text { Late } 19^{\text {th }} \text { to } \\
\text { Mid- } 20^{\text {th }} \\
\text { century }\end{array}$ & $\begin{array}{l}2^{\text {nd }} \text { half of } 20^{\text {th }} \\
\text { century }\end{array}$ & $\begin{array}{c}\text { Early } 21^{\text {st }} \\
\text { century }\end{array}$ \\
\hline $\begin{array}{c}\text { Mode of } \\
\text { Production }\end{array}$ & $\begin{array}{c}\text { Steam engine and } \\
\text { mechanical } \\
\text { production }\end{array}$ & $\begin{array}{l}\text { Electricity and } \\
\text { division of } \\
\text { labor }\end{array}$ & $\begin{array}{c}\text { Electronics and } \\
\text { information } \\
\text { technology }\end{array}$ & $\begin{array}{c}\text { ICT } \\
\text { technologies }\end{array}$ \\
\hline $\begin{array}{l}\text { Production } \\
\text { Structure }\end{array}$ & Industrial Cities & $\begin{array}{l}\text { Industrial } \\
\text { region }\end{array}$ & $\begin{array}{c}\text { Global production } \\
\text { networks }\end{array}$ & $\begin{array}{l}\text { Global value } \\
\text { chains }\end{array}$ \\
\hline
\end{tabular}

The fourth industrial revolution or Industry 4.0 is emerging due to exponential evolution of modern technologies, which includes Internet of Things (IoT), cloud computing, advanced algorithms, artificial intelligence, hyper-connectivity, self-learning systems, automation, big data and analytics [14], [15]. These disruptive technologies are the basic building blocks of this fourth industrial revolution [16], [17], while digitalization or digital transformation is basic requirement for organizations to advance in this fourth industrial age [13]. These technologies possess such capabilities that can exponentially enhance the productivity of firms by offering new functionality, higher reliability, greater efficiency, and optimization possibilities that pose both opportunities and challenges for people and organizations [13]. In following, figure1 [1], [13] provides an overall picture of industry 4.0 enabling technologies and organizational requirements in terms of technical and managerial issues for its successful implementation.

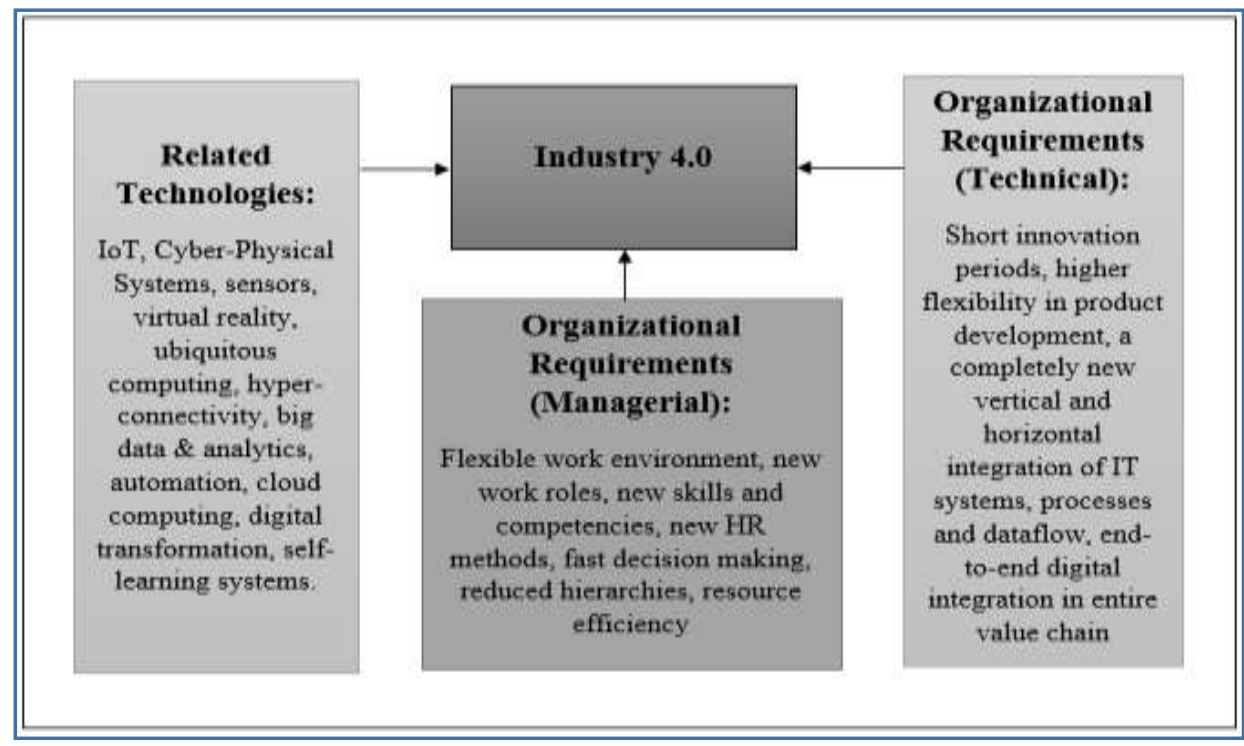

Figure 1. Overview of Industry 4.0 
According to Lasi et al. [13], to comply with this fourth industrial age, organizations need to change themselves according to industry 4.0 requirements. It includes short development and innovation periods, a change from a seller's into a buyer's market viewpoint, higher flexibility in product development, decentralization to cope with the specified conditions, faster decision-making measures, reduced organizational hierarchies and resource efficiency [9]. Explaining it further, Oesterreich et al. [9] argue that there will be wide spread of increasing mechanization, automation, digitalization, networking and miniaturization, which will enhance organizational manufacturing and operational capabilities. Lasi et al. [13] also explains key features required for the implementation of industry 4.0. It includes integration of IT systems, processes and data flows between different stakeholders like customers, suppliers and external partners (also known as horizontal integration), end-to-end digital integration of engineering through the entire value chain to enable highly customized products and integration of IT systems, processes and data flows within the company from product development to manufacturing, logistics and sales for cross functional collaboration (also known as vertical integration) [16], [18] [19], [20].

To implement industry 4.0 concept successfully in any organization, the system designers must consider both technical and social challenges. Most of the recent studies have focused on technical part of industry 4.0 [7], [19], which raises the need for managerial research in this field. Therefore, we have limited the scope of this paper to discuss only managerial aspects of industry 4.0. In next section, we discuss sociotechnical system theory for the implementation of industry 4.0 .

\section{Sociotechnical System Theory}

Sociotechnical systems thinking emerged out of work steered at the UK Tavistock Institute into the introduction of coal mining machinery, which identified the interconnected nature of technological and social characteristics of the workplace [20], [21]. The introduction of new machinery into coalmines without analysis of the associated changes in working practices stressed the need for consideration of social issues during the design and implementation of new technologies [4]. The term sociotechnical system is applied to describe systems that involve a multifarious interaction between humans, machines and the environmental characteristics of organizational systems [20]. The STS theory considers both technical and social factors when seeking to promote change within an organization, whether it is related to the introduction of new technology or an organizational change program [4], [20]. Organizations are complex systems, which involve many interdependent factors. Therefore, to design change in one part of the system without considering how this can affect, or require change, in the other parts of the system will limit its effectiveness [5]. That is why, organizations need to adopt holistic approach when designing a new system in 
organization, especially, they must consider social and technical aspects of it to enhance its efficiency and effectiveness. There is wide recognition that considering the social and technical interactions has practical significance in organizational development predominantly when seeking to promote change [22], that makes STS theory a comprehensive and holistic approach for such purposes.

In the early stage of STS theory, it was used to analyze existing systems to reveal dysfunctions between what people in the social system were trying to accomplish and what the technical system aided [5]. Such analysis helped in improving effectiveness of sociotechnical systems. As per such systems cannot be designed without the commitment of people, who will be users of it, so it led user-participative methods for new system designs [23]. Such objectives led to a series of methodological developments like HUFIT project, ORDIT project [5], ETHICS [5] and Multiview [5]. In past decade, STS theory is widely spread across many disciplines [24]. On one hand, this widespread shows the success of STS theory while on the other hand, it caused loss of conceptual foundations of it [5]. Looking at future challenges for STS theory, organizations and work environments are changing fast [3], [5]. The new technologies are much more disruptive as compare to past, which require exponential changes in all industrial areas[25]. So STS theory must consider such issues to contribute in the changing nature of work systems in future. [5] Table 2 summarizes the overview of STS theory in historical prospect.

Table 2. Overview of STS Theory [5]

\begin{tabular}{|c|c|}
\hline \multicolumn{2}{|r|}{ Overview of STS Theory } \\
\hline $\begin{array}{l}\text { Early Mid 90s } \\
\quad \text { Late 90s }\end{array}$ & $\begin{array}{ll}\text { - } & \text { Creation of STS Theory by Trist \& Bamforth } \\
\text { - } & \text { Analysis of existing systems } \\
\text { - } & \text { User-participative methods for new systems design } \\
\text { - } & \text { Methodological developments } \\
\text { - } & \text { STS theory as design approach } \\
\text { - } & \text { Projects like HUSAT, ORDIT, ETHICS \& Multiview }\end{array}$ \\
\hline Present (21 ${ }^{\text {st }}$ Century $)$ & $\begin{array}{l}\text { Wide spread of STS in many disciplines like Ergonomics, } \\
\text { Psychology, Human-Computer Interaction, Sociology, } \\
\text { Management and Organizational Theory } \\
\text { Due to this widespread, STS theory is losing its roots in } \\
\text { terms of its basics principles and conceptual foundations. }\end{array}$ \\
\hline Future (New industrial age) & $\begin{array}{l}\text { STS should address: } \\
\text { - Changing characteristics of organizations, growing use of } \\
\text { IT, network of suppliers rather simple work processes, } \\
\text { development of work systems which is now extended } \\
\text { across a number of organizations } \\
\text { - Trans-organizational work systems } \\
\text { - Emerging forms of new technologies e.g. social media } \\
\text { services }\end{array}$ \\
\hline
\end{tabular}


If we look at each industrial revolution as described in table 1, each paradigm has its own new technology, which steered new ways of working and interaction between technology and humans[24]. The classic "factory system of manufacturing" was introduced during first industrial paradigm, second industrial revolution brought division of labor and third revolution transferred the responsibilities of manual worker to one of control worker [25]. Similarly, this fourth-industrial revolution is also introducing new ways of work e.g. decoupling of work and place, decoupling of work and employment and decoupling of work and time, which is leading towards flexible work environment and requires new skills and competencies [26]. It is very clear that stakeholders at all levels will need to change their approach towards how they work, but at the moment, new research is very essential to understand the full sociotechnical impact of fourth industrial revolution on how people can work effectively and what competencies they require in this digital environment [26], [27]. In the next section, we discuss the competence-based view to discuss industry 4.0.

\section{Competence Based View}

Due to ever-changing advanced technologies, organizations are facing turbulent and changing environment, which raises the need for flexibility in work organization and job design to stay competitive [26], [27]. In human resource management, it has replaced the traditional job based approach with competency-based systems [26]. According to Campion et al. [28], in competency based approach, organizations aim to identify the competencies that are critical to job performance, and allocate tasks to employees based on the competencies they have, rather than on the position they hold in the organization (as is the case for traditional HRM systems). Therefore, competence based HRM focuses on employee's competencies instead of job and its requirements [29], [30]. It allows more flexible organization of work then the traditional job based approach [26], [28]. According to the resource-based view, competency management is an important tool for maintaining organizational competitiveness [31]. By defining those competencies that are needed to successfully implement the organizational strategy, organizations create resources that, in turn, contribute to sustained competitive advantage [32].

To cope with challenges related to industry 4.0, organizations need to adopt competencebased view, which will help organizations to identify critical competencies to develop their workforce to meet present and future market needs [31]. Competencies can be defined as "an underlying characteristic of an individual that is causally related to criterion-referenced effective and/ or superior performance in a job or a situation" [32]. These competencies can be categorized in four main classes. Firstly, technical competencies comprise all job-related knowledge and skills. Secondly, methodological competencies include all skills and abilities for general problem solving and decision-making. Thirdly, social competencies encompass all skills and abilities as well as the attitude to cooperate and communicate with others. Finally, personal competencies include an individual's social values, motivations, and attitudes [33]. 
Figure 2 provides overview of how competence based view can contribute towards development of new competence models for emerging new work roles and new job profiles. It also shows the role of Evolute system approach, i.e. based on competence-based view; we can develop new competence models in Evolute system, which will help in successful implementation of Industry 4.0.

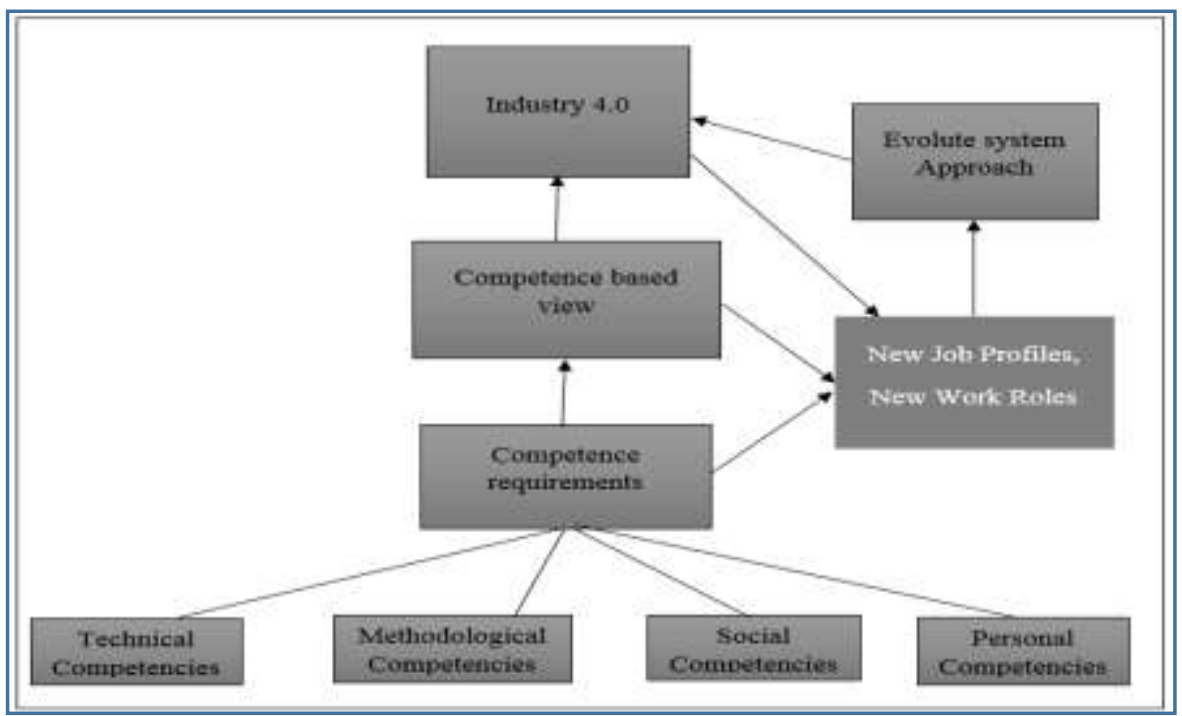

Figure 2. Research framework from $C B V$ prospect

A very critical step for competency identification \& development is to identify that what kind of new work roles of existing jobs are emerging due to industry 4.0. For example, new work roles of system designers, who are designing new industry 4.0 systems for the organizations, new work roles of HR managers, who now have to deal with big data and analytics for different HR practices and so on [1]. Similarly, new job profiles are also emerging in the organizations, which require different and higher levels of competencies [11], [12], e.g. data scientists and electro-mechanical engineers [10]-[12]. Therefore, to address the challenges related to competency development of these new work roles and new job profiles, organizations need to use competence models like Evolute system approach. In next section, we discuss Evolute approach and future research agenda for it.

\section{Evolute Approach}

The Evolute approach can be proved as very important competence model tool, which will not only help organizations in competency development of employees but also in developing/analyzing different processes. Previously, it has been used for competency identification, competency development and talent identification [12]. It is based on the 
emerging co-Evolute methodology and brain-based metaphors, which enable one to visualize in the form of different graphs and examine the current reality and personal vision of individuals/employees and business processes [10], [12]. The idea of co-Evolute methodology is based on the concept that organizations aim to support employees' personal growth, vision and development in order to improve their own core competencies [10]. This strategy helps both organization and employees, in evolution towards excellence that is why, it is called co-Evolute system or co-evolutionary methodology [10].

The Evolute system is a platform that supports building and using co-evolutionary applications [10]. It utilizes fuzzy logic to capture the subjective, abstract and vague nature of individual's current occupational competencies [34]. Fuzzy logic also facilitates approximate reasoning for analyzing and modelling different levels of creative tension according to the occupational competencies and based on individuals' perception of their current reality and vision [34]. According to Senge [34], creative tension is the difference between personal vision and current reality. It motivates individuals and organizations to develop their-selves to achieve their future vision. Currently, the Evolute system consist of thirty-seven tools, which are designed for different work roles, cultures and processes. For example, tool Astroid is designed to analyze the competencies of sales personnel, Bicorn and Serpentine for safety culture, Cochleoid for competencies of buyers, Conchoid for competencies of maintenance personnel, Cycloid for competencies of project managers and so on [35].

In this new industrial age, Evolute system can play a vital role in competency identification and development for emerging new work roles and job profiles. Most of the existing competence models in the Evolute system were developed in the first decade of current century. A lot has been changed since the introduction of Industry 4.0 era, which raises the need of reviewing and updating the existing competence models of Evolute system as well as developing the new competence models. We propose following research agenda for Evolute system approach to support the Industry 4.0:

- Comprehensive review of existing competence models and update them according to need of industry 4.0

- Identification of new work roles of existing job profiles and update the related competence models of Evolute system accordingly e.g. Tool CYCLOID evaluates project managers, which was developed in 2006 [36]. There has been many changes in the field of project management e.g. more usage of project management tool box (digital tools)[37], which raises the need of competency upgradation of project managers [16], [17]. So such updates are required to enhance the effectiveness of such tools.

- Identification of new job profiles and competence model development for them, for example, competence model for system engineers need to be developed in the Evolute system as system engineers are the one, who develop industry 4.0 related systems for organizations. Similarly, new job profiles which are driving this 
revolution are technical experts (control engineers, computer scientists), data analysts (creating business intelligence from integrating the large data sets) and knowledge workers [21], which raises the need of competence model development for it.

- Identification of new cultures of organizations and development of competence models for it e.g. there is need of "digital culture" application in Evolute system as its one of the fastest emerging culture in the organizations due to digitalization phenomenon, which is leading towards industry 4.0.

\section{Discussion}

In this study, firstly, we examined the concept of Industry 4.0 with respect to its definition, related technologies and current challenges. We found that new technologies of this industrial age are much more disruptive as compare to past three industrial revolutions, which can exponentially enhance the productivity of firms by offering new functionality, higher reliability, greater efficiency, and optimization possibilities that pose both opportunities and challenges for people and organizations [3]. It raises the need of big organizational change in all aspects i.e. organizational structures, culture, horizontal and vertical integration, organizational and personnel competences, management styles, human resource practices and so on. We limited the scope of this study by focusing only on social and managerial aspects of industry 4.0.

Secondly, we reviewed sociotechnical system theory in historical aspect. We summarized past work on STS theory, current status of it and future issues that STS theory should address. Based on this review, we highlighted the need of understanding sociotechnical impact of industry 4.0 in the organizations. We conclude that, organizations must consider sociotechnical impact of new technological systems in their organizations as it is widely acknowledged that adopting a sociotechnical approach to system development leads to systems that are more acceptable to end users and deliver better value to stakeholders [1], [13].

Thirdly, we argue that, personnel competencies are the most critical success factor to implement and operate the industry 4.0 systems in the organization, whether it's, technical requirements, managerial issues, or other challenges related to it, organizations must need specific competencies in their experts/human capital, who are dealing with these issues. To meet those competency requirements, this research paper proposes that organizations need to adopt competence-based view to analyze their human capital strengths/weaknesses and to develop them accordingly.

Lastly, we argue that, for the purpose of competency analysis and personnel competency development, organizations can use Evolute system approach, which provides different competence models for such purposes. As Industry 4.0 is relatively new phenomenon, therefore, Evolute approach should review its existing competence models in the light of 
fourth-industrial age's requirements, and develop new competence models for experts such as system engineers, technical experts, data analysts and other emerging job profiles.

\section{Conclusion}

The present study provides a significant contribution to the literature of industry 4.0, STS theory, CBV and Evolute approach. It offers useful insights for organizations that they must consider social factors and competency requirements for designing, implementing and maintaining Industry 4.0 systems. The research model (Fig. 2) that we have presented can be an important stepping-stone for the HR \& Evolute scholars/practitioners for the contribution towards competency development according to the needs of industry 4.0. Moreover, the study reported in this article was the first to explore future research agenda for Evolute approach to enhance the organizational compatibility with industry 4.0 through personnel development. We hope that this study will inspire further theory building and future research on how organizations can manage their industry 4.0 systems in terms of social factors (through STS theory), competence development (through CBV) and competence model development (through Evolute system).

\section{References}

1. A. Gilchrist, Industry 4.0: The Industrial Internet of Things. 2016.

2. L. Gehrke, R. Bonse, and M. Henke, "Towards a management framework for the digital transformation of logistics and manufacturing," 23rd EurOMA Conf., no. June, pp. 1-10, 2016.

3. B. Lanvin and O. Evans, The Global Talent Competitiveness Index 2017: Talent and Technology, vol. 49, no. 6. Fontainebleau, France: INSEAD, 2016.

4. A. Cherns, "The Principles of Sociotechnical Design," Hum. Relations, vol. 29, no. 8, pp. 783792, 1976.

5. K. Eason, "Afterword: The past, present and future of sociotechnical systems theory," Appl. Ergon., vol. 45, no. 2 Part A, pp. 213-220, 2014.

6. E. Trist and K. Baumforth, "Some social and psychological consequences of the longwall method of coal getting," Human Relations, vol. 4, no. 38. pp. 7-9, 1951.

7. E. Trist, "The Evolution of socio-technical systems: a conceptual framework and action research program," Conference on Organizational Design and Performance, vol. 2. pp. 1-67, 1980.

8. H. Fatorachian and H. Kazemi, "A critical investigation of Industry 4.0 in manufacturing: theoretical operationalisation framework," Prod. Plan. Control, vol. 7287, pp. 1-12, 2018.

9. T. D. Oesterreich and F. Teuteberg, "Understanding the implications of digitisation and automation in the context of Industry 4.0: A triangulation approach and elements of a research agenda for the construction industry," Comput. Ind., vol. 83, pp. 121-139, 2016.

10. J. I. Kantola, H. Vanharanta, and W. Karwowski, "The Evolute system: a co- evolutionary human resource development methodology," in International Encyclopedia of Ergonomics and Human Factors, 2006, pp. 1-19.

11. F. Imran and J. I. Kantola, "A Co-evolute Approach to Analyze the Competencies of Sales Personnel of Banking Sector of Pakistan," in Advances in Human Factors, Business Management and Leadership, Los Angeles, California, USA: Springer, 2017, pp. 125-136.

12. F. Imran and J. I. Kantola, "Evolute System Approach and Identification of Talent," in 86th IASTEM International Conference, 2017, pp. 11-16. 
13. H. Lasi, P. Fettke, H. G. Kemper, T. Feld, and M. Hoffmann, "Industry 4.0," Bus. Inf. Syst. Eng., vol. 6, no. 4, pp. 239-242, 2014.

14. C. Lerch and M. Gotsch, "Digitalized Product-Service Systems in Manufacturing Firms: A Case Study Analysis," Res. Manag., vol. 58, no. 5, pp. 45-52, 2015.

15. V. Parida, D. R. Sjödin, J. Wincent, and M. Kohtamäki, "Mastering the transition to productservice provision: Insights into business models, Learning activities, and capabilities," Res. Technol. Manag., vol. 57, no. 3, pp. 44-52, 2014.

16. M. E. Porter and J. E. Heppelmann, "How smart, connected products are transforming companies," Harvard Business Review, vol. 2015, no. October. 2015.

17. K. Schwab, The Fourth Industrial Revolution. 2016.

18. M. Iansiti and K. R. Lakhani, "Digital ubiquity: How connections, sensors, and data are revolutionizing business," Harv. Bus. Rev., no. November 2014, 2014.

19. E. L. Trist and K. W. Bamforth, "Some Social and Psychological Consequences of the Longwall Method of Coal-Getting: An Examination of the Psychological Situation and Defences of a Work Group in Relation to the Social Structure and Technological Content of the Work System," Hum. Relations, vol. 4, no. 1, pp. 3-38, 1951.

20. M. C. Davis, R. Challenger, D. N. W. Jayewardene, and C. W. Clegg, "Advancing sociotechnical systems thinking: A call for bravery,” Appl. Ergon., vol. 45, no. 2 Part A, pp. 171-180, 2014.

21. G. Baxter and I. Sommerville, "Socio-technical systems: From design methods to systems engineering," Interact. Comput., vol. 23, pp. 4-17, 2011.

22. L. Damodaran, "User involvement in the systems design process-a practical guide for users," Behav. Inf. Technol., vol. 15, no. 6, pp. 363-377, 1996.

23. E. Mumford, “A Socio-Technical Approach to Systems Design,” Requir. Eng., vol. 5, no. 2, pp. $125-133,2000$.

24. E. Brynjolfsson and A. McAfee, The Second Machine Age, First. New York, USA: Norton \& Company, 2014.

25. R. Davies, T. Coole, and A. Smith, "Review of Socio-technical Considerations to Ensure Successful Implementation of Industry 4.0," Procedia Manuf., vol. 11, no. June, pp. 1288-1295, 2017.

26. A. De Vos, S. De Hauw, and I. Willemse, “An integrative model for competency development in organizations: the Flemish case," Int. J. Hum. Resour. Manag., vol. 26, no. 20, pp. 2543-2568, 2015.

27. M. Vakola, K. Eric Soderquist, and G. P. Prastacos, "Competency management in support of organisational change," Int. J. Manpow., vol. 28, no. 3/4, pp. 260-275, 2007.

28. M. a Campion and R. B. Odman, "Doing competencies well: Best practice in competency modelling," Pers. Psychol., vol. 64, pp. 225-262, 2011.

29. A. A. Lado and M. C. Wilson, "Human resource systems and sustained competitive advantage: A competency based perspective," Acad. Manag. Rev., vol. 19, no. 4, pp. 699-727, 1994.

30. P. M. Wright, G. C. Mcmahan, and A. Mcwillams, "Human resources and sustained competitive advantage: A resource-based perspective," Int. J. Hum. Resour. Manag., vol. 5, no. 2, pp. 301326, 1994.

31. F. Hecklau, M. Galeitzke, S. Flachs, and H. Kohl, "Holistic Approach for Human Resource Management in Industry 4.0," Procedia CIRP, vol. 54, pp. 1-6, 2016.

32. L. M. Spencer and S. M. Spencer, "Competence at Work : Models for Superior Performance," John Wiley Sons, pp. 1-372, 1993.

33. European Commission, "The Future of Work Skills and Resilience for a World of Change EPSC Strategic Notes The World of Work Has Always Evolved Opportunities, Disruptions and 
Transitions," EPSC Strateg. Notes, no. 13, p. 12, 2016.

34. P. Senge, The fifth discipline: the art and practice of the learning organization. New York, USA: Currency Doubleday, 1990.

35. J. I. Kantola, Organizational Resource Management- Theories, Methodologies and Applications. CRS Press, 2015.

36. K. Liikamaa, "Developing a Project Manager's Competencies: A Collective View of the Most Important Competencies," Procedia Manuf., vol. 3, no. Ahfe, pp. 681-687, 2015.

37. D. Z. Milosevic and R. J. Martinelli, Project Management Toolbox: Tools and Techniques for the Practicing Project Manager. John Wiley \& Sons, 2016. 